\title{
Discovery of an Oxepine-containing Diketopiperazine Derivative Active Against Concanavalin A-Induced Hepatitis
}

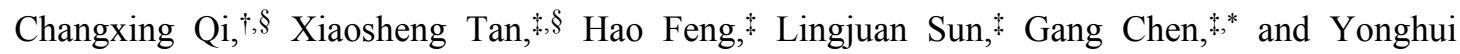
Zhang ${ }^{\dagger, *}$

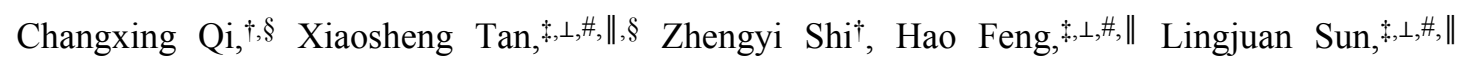
Zhengxi Hu, ${ }^{\dagger, *}$ Gang Chen, $,+,, \#, \|, *$ and Yonghui Zhang ${ }^{\dagger, *}$

${ }^{\dagger}$ Hubei Key Laboratory of Natural Medicinal Chemistry and Resource Evaluation, Tongji Medical College, Huazhong University of Science and Technology, Wuhan 430030, Hubei Province, People's Republic of China

Institute of Organ Transplantation, Tongji Hospital, Tongji Medical College, Huazhong University of Science and Technology, Wuhan 430030, Hubei Province, People's Republic of China

${ }^{\perp}$ Key Laboratory of Organ Transplantation, Ministry of Education, Wuhan 430030, Hubei Province, People's Republic of China

\#NHC Key Laboratory of Organ Transplantation, Wuhan 430030, Hubei Province, People's Republic of China

\|Key Laboratory of Organ Transplantation, Chinese Academy of Medical Sciences, Wuhan 430030, Hubei Province, People's Republic of China

\section{*Corresponding Authors:}


E-mails: huzhengxi@hust.edu.cn (Z. Hu); gchen@tjh.tjmu.edu.cn (G. Chen); zhangyh@mails.tjmu.edu.cn (Y. Zhang)

§These authors have contributed equally to this work.

\begin{tabular}{|c|c|}
\hline Contents & Pages \\
\hline Table S1. ${ }^{1} \mathrm{H}$ and ${ }^{13} \mathrm{C}$ NMR data for 1 (Record in $\mathrm{CDCl}_{3} ; J$ in $\mathrm{Hz}$ ). & 3 \\
\hline $\begin{array}{l}\text { Table S2. Extent of inhibition of } 1 \text { against the proliferation of Con-A induced } \\
\text { murine splenocytes. }\end{array}$ & 4 \\
\hline Figure S1. Key 2D correlations of compounds $\mathbf{1}$. & 4 \\
\hline $\begin{array}{l}\text { Figure S2. Impact of compound } \mathbf{1} \text { on anti-CD3/anti-CD28 mAb-stimulated } \\
\text { splenocytes proliferation in vitro. }\end{array}$ & 5 \\
\hline $\begin{array}{l}\text { Figure S3. Compound } \mathbf{1} \text { inhibited the production of IL-2, IFN- } \gamma \text {, TNF- } \alpha \text {, } \\
\text { IL-4, IL-6 and IL-10 in mouse splenocytes. }\end{array}$ & 6 \\
\hline Figure S4. Cell viability of $\mathbf{1}$ was assessed through CCK assay. & 6 \\
\hline Figure S5. ${ }^{1} \mathrm{H}-\mathrm{NMR}\left(400 \mathrm{MHz}, \mathrm{CDCl}_{3}\right)$ spectrum of compound $\mathbf{1}$ & 7 \\
\hline Figure S6. ${ }^{13} \mathrm{C}-\mathrm{NMR}\left(100 \mathrm{MHz}, \mathrm{CDCl}_{3}\right)$ spectrum of compound $\mathbf{1}$ & 7 \\
\hline Figure S7. HSQC spectrum of compound $\mathbf{1}$ & 8 \\
\hline Figure S8. HMBC spectrum of compound 1 & 8 \\
\hline Figure S9. ${ }^{1} \mathrm{H}-{ }^{1} \mathrm{H}$ COSY spectrum of compound $\mathbf{1}$ & 9 \\
\hline Figure S10. NOESY spectrum of compound $\mathbf{1}$ & 9 \\
\hline Figure S11. HR-ESI-MS spectrum of compound 1 & 10 \\
\hline Figure S12. UV spectrum of compound 1 & 10 \\
\hline
\end{tabular}


Table S1. ${ }^{1} \mathrm{H}$ and ${ }^{13} \mathrm{C} \mathrm{NMR}$ data for $\mathbf{1}\left(\right.$ Record in $\mathrm{CDCl}_{3} ; J$ in $\mathrm{Hz}$ ).

\begin{tabular}{|c|c|c|}
\hline \multirow{2}{*}{ no. } & \multicolumn{2}{|c|}{1} \\
\cline { 2 - 3 } & $\delta_{\mathrm{H}}$ & $\delta_{\mathrm{C}}$ \\
\hline 1 & 7.61 & 165.1 \\
\hline $2(\mathrm{NH})$ & & 121.2 \\
\hline 3 & & 118.6 \\
\hline 4 & & \\
\hline
\end{tabular}




\begin{tabular}{|c|c|c|}
\hline 6 & & 154.4 \\
\hline 8 & $6.55 \mathrm{~d}(7.4)$ & 143.6 \\
\hline 9 & $5.28 \mathrm{dd}(7.4,7.4)$ & 102.5 \\
\hline 10 & $5.99 \mathrm{dd}(7.4,9.9)$ & 127.9 \\
\hline 11 & $5.85 \mathrm{~d}(9.9)$ & 128.3 \\
\hline 12 & & 76.0 \\
\hline 13 & & 110.8 \\
\hline 15 & $4.59 \mathrm{~m}$ & 56.3 \\
\hline 16 & $3.05 \mathrm{dd}(7.3,14.9)$ & 32.0 \\
\hline 17 & $0.9 \mathrm{~d}(7.1)$ & 18.8 \\
\hline 18 & $1.31 \mathrm{~m}$ & 27.2 \\
\hline 19 & $0.95 \mathrm{t}(7.4)$ & 12.4 \\
\hline 20 & $3.78 \mathrm{~d}(11.3) ; 3.96 \mathrm{~d}(11.7)$ & 63.0 \\
\hline 21 & $3.96 \mathrm{~m}$ & 79.5 \\
\hline 22 & & 81.4 \\
\hline 23 & $1.57 \mathrm{~s}$ & 21.9 \\
\hline 24 & $1.54 \mathrm{~s}$ & 28.6 \\
\hline 1 ' & $3.15 \mathrm{dd}(10.7,13.6) ; 3.29 \mathrm{dd}(4.9,13.7)$ & 35.3 \\
\hline 2 ' & & 136.8 \\
\hline $3^{\prime}, 7^{\prime}$ & $7.18, \mathrm{~m}$ & 129.2 \\
\hline $4^{\prime}, 6^{\prime}$ & $7.21, \mathrm{~m}$ & 128.3 \\
\hline $5^{\prime}$ & $7.16, \mathrm{~m}$ & 126.6 \\
\hline
\end{tabular}


Table S2. The inhibition rates of 1 against the proliferation of Con-A induced murine splenocytes

\begin{tabular}{ccccc}
\hline Compound & \multicolumn{4}{c}{ Inhibition rates (\%) } \\
\cline { 2 - 5 } & $64 \mathrm{nM}$ & $128 \mathrm{nM}$ & $256 \mathrm{nM}$ & $512 \mathrm{nM}$ \\
\hline $\mathbf{1}$ & 20 & 28 & 43 & 80 \\
FK506 & - & - & - & 83 \\
\hline
\end{tabular}

FK506 was used as positive control and "-" means not tested.

Figure S1. Key 2D correlations of compounds 1. 

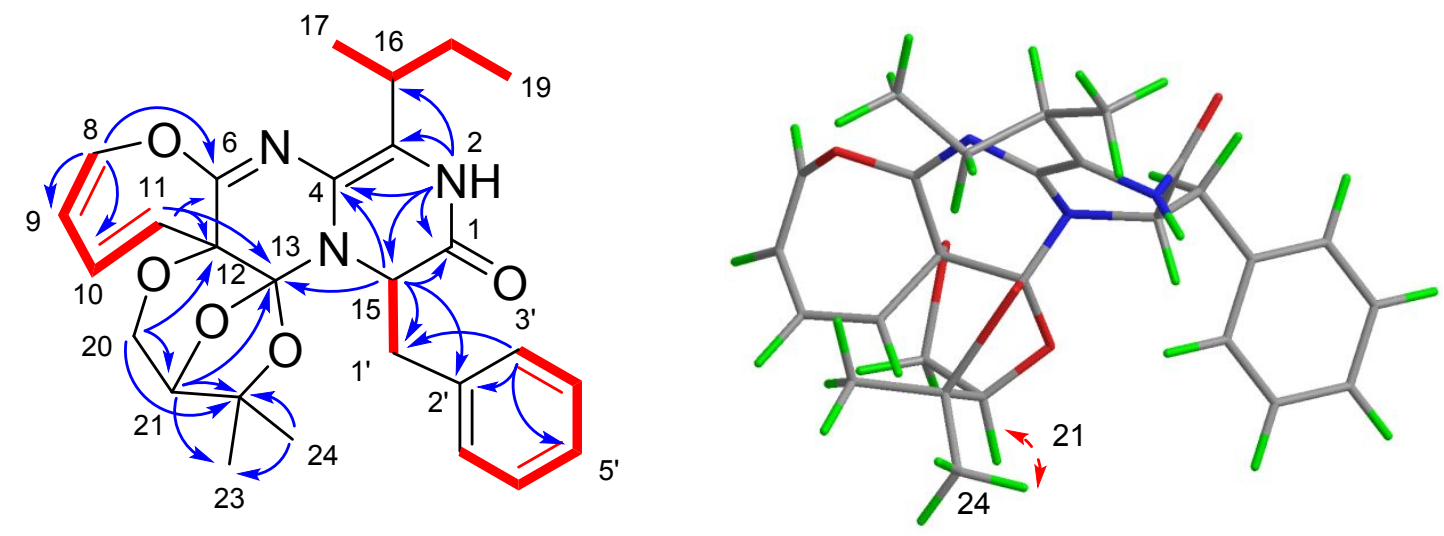

- COSY ح HMBC 
Figure S2. Impact of compound 1 on anti-CD3/anti-CD28 mAb-stimulated splenocytes proliferation in vitro.

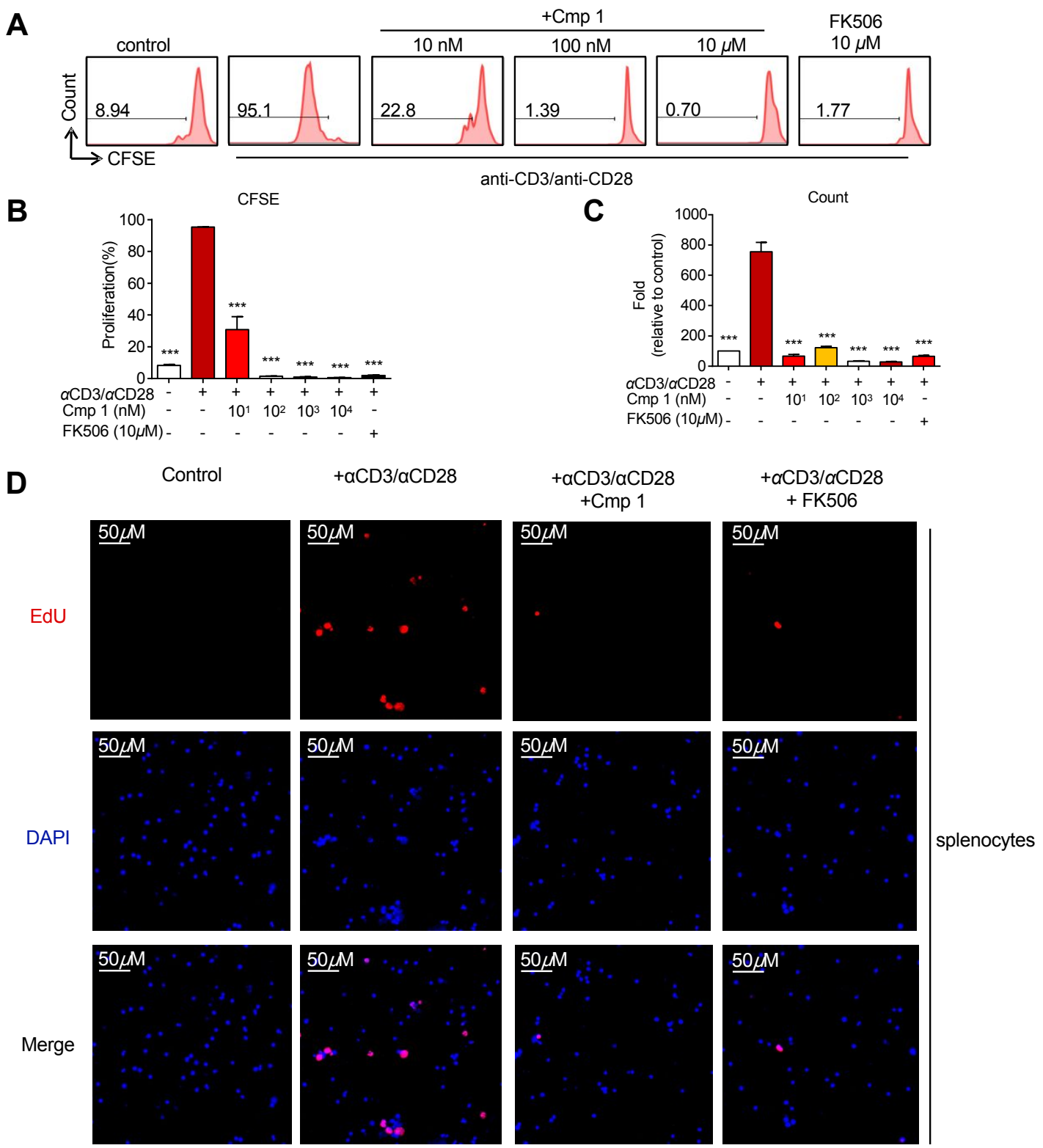

(A) Splenocytes were labelled with CFSE and then cultured with stimuli, anti-CD3/anti-CD28 mAbs with or without compound 1 as shown for $72 \mathrm{~h}$. CFSE dilutions display proliferation. (B) (C) Proliferation of anti-CD3/anti-CD28 mAb-stimulated splenocytes in different concentrates. (D) EdU staining determined the effect of compound 1 on the proliferation of splenocytes. The means \pm SEM of three replicates are shown; ${ }^{* * *}$ indicates $p<0.001$. 
Figure S3. Compound 1 inhibited the production of IL-2, IFN- $\gamma$, TNF- $\alpha$, IL-4, IL-6 and IL-10 in mouse splenocytes.

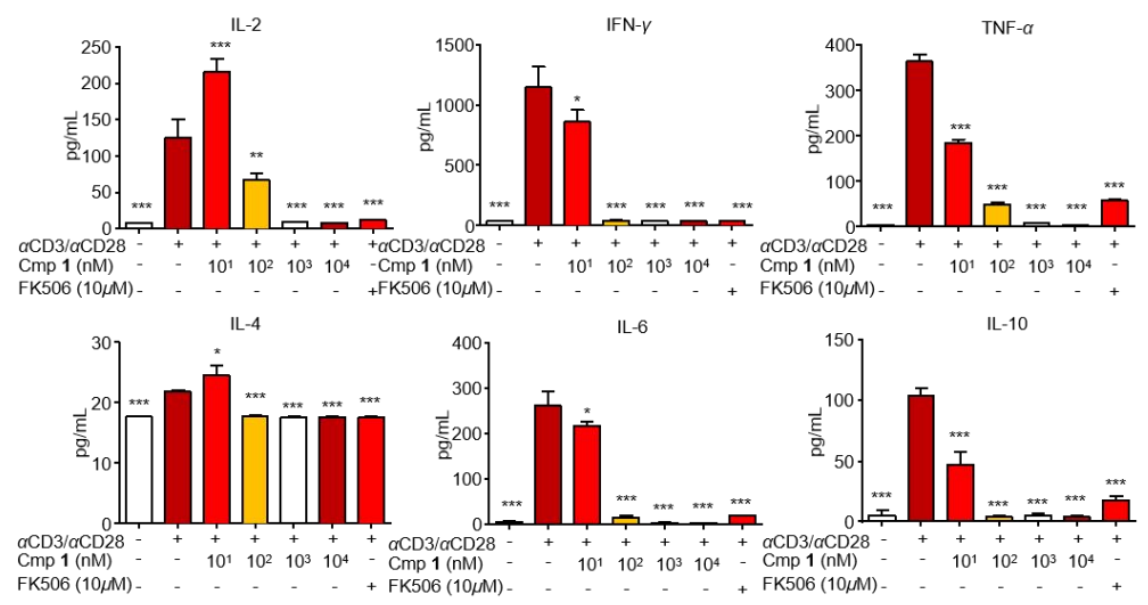

Mouse splenocytes were treated with 10 to $10000 \mathrm{nM} \mathrm{Cmp} 1$ for $16 \mathrm{~h}$ and then subsequently stimulated with anti-CD3/CD28 mAbs for $72 \mathrm{~h}$. After stimulation, supernatants were harvested, and the levels of IL-2, IFN- $\gamma$, TNF- $\alpha$, IL-4, IL-6 and IL-10 were measured by cytometric bead array. The means \pm SEM of three replicates are shown; *indicates $0.01<p<0.05,{ }^{* *}$ indicates $0.001<p<0.01$, and ${ }^{* * *}$ indicates $p<$ 0.001 .

Figure S4. Cell viability of 1 was assessed through CCK assay. Splenocytes were treated with $0,1,10$ and $100 \mu \mathrm{M}$. The exposure of splenocytes to 1 at concentrations up to $100 \mu \mathrm{M}$ had no effect on cell viability. 


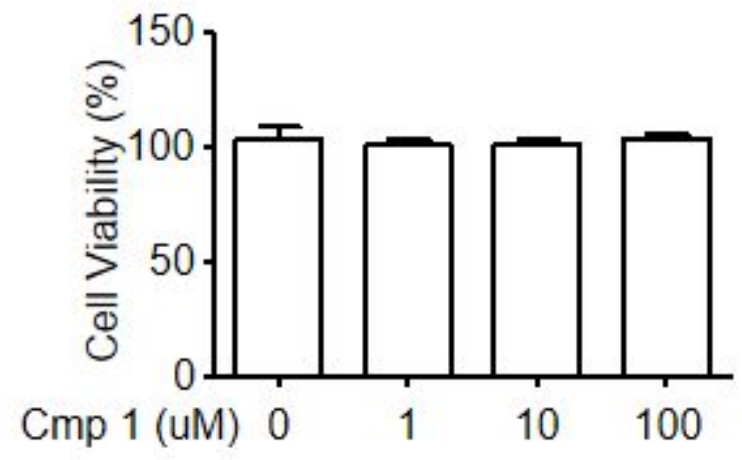

Figure S5. ${ }^{1} \mathrm{H}-\mathrm{NMR}\left(400 \mathrm{MHz}, \mathrm{CDCl}_{3}\right)$ spectrum of compound $\mathbf{1}$ 


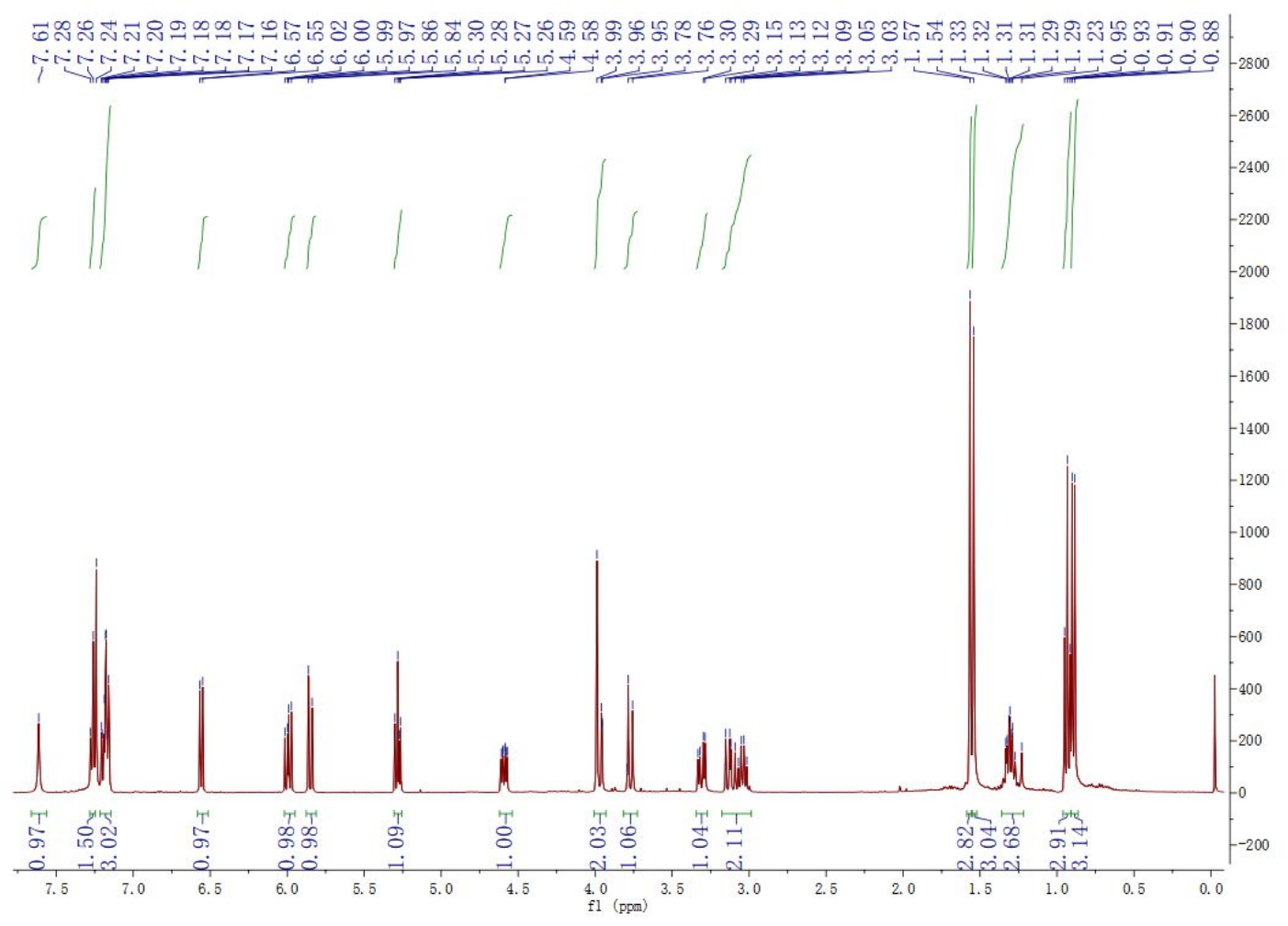

Figure S6. DEPT 135 and ${ }^{13} \mathrm{C}-\mathrm{NMR}\left(100 \mathrm{MHz}, \mathrm{CDCl}_{3}\right)$ spectrum of compound $\mathbf{1}$
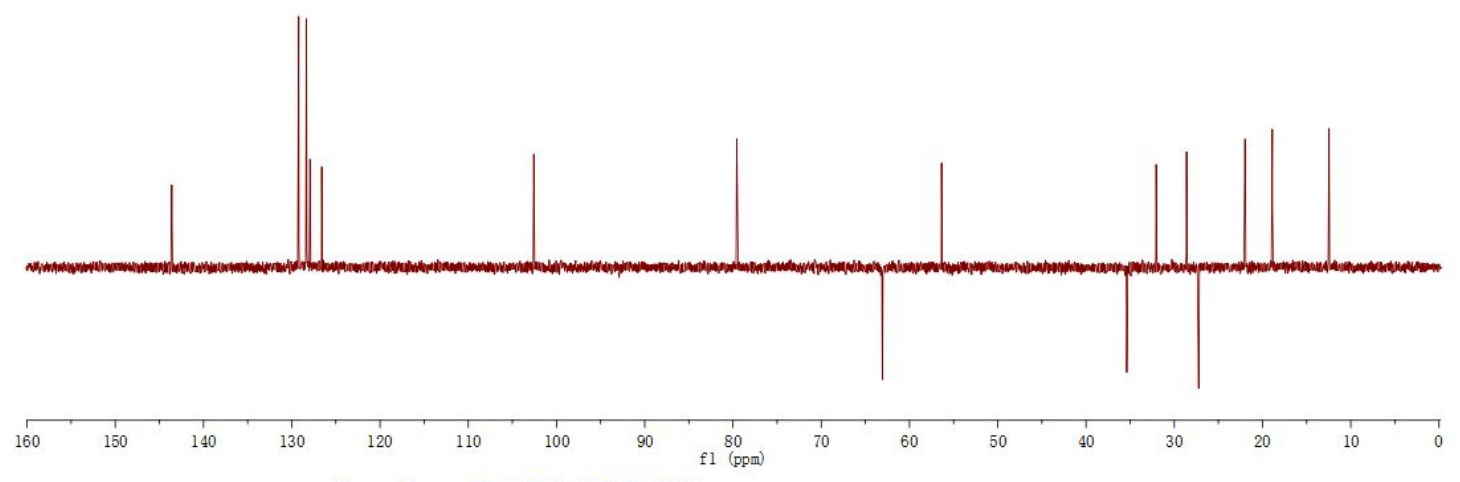

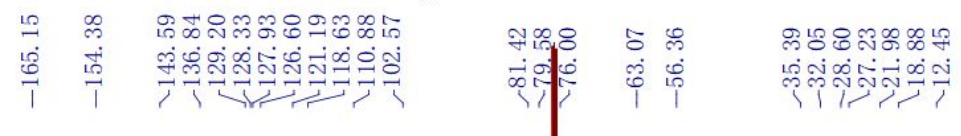

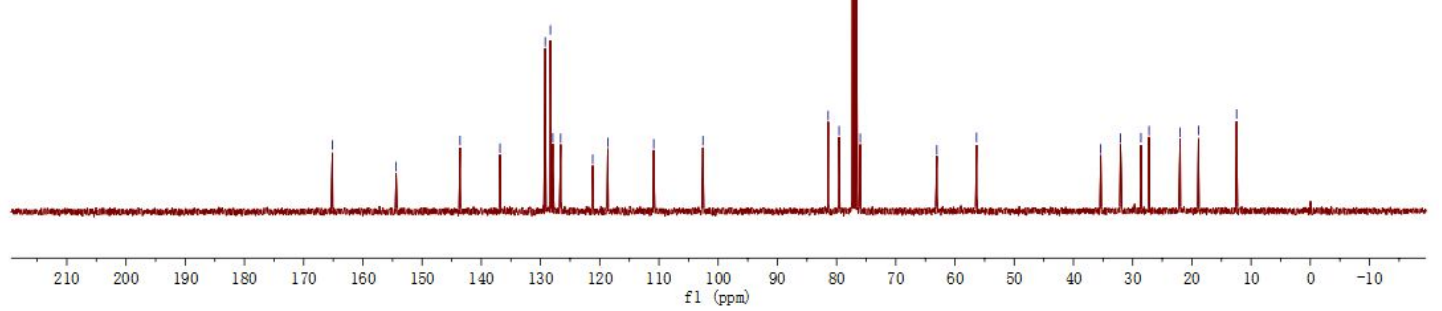


Figure S7. HSQC spectrum of compound 1

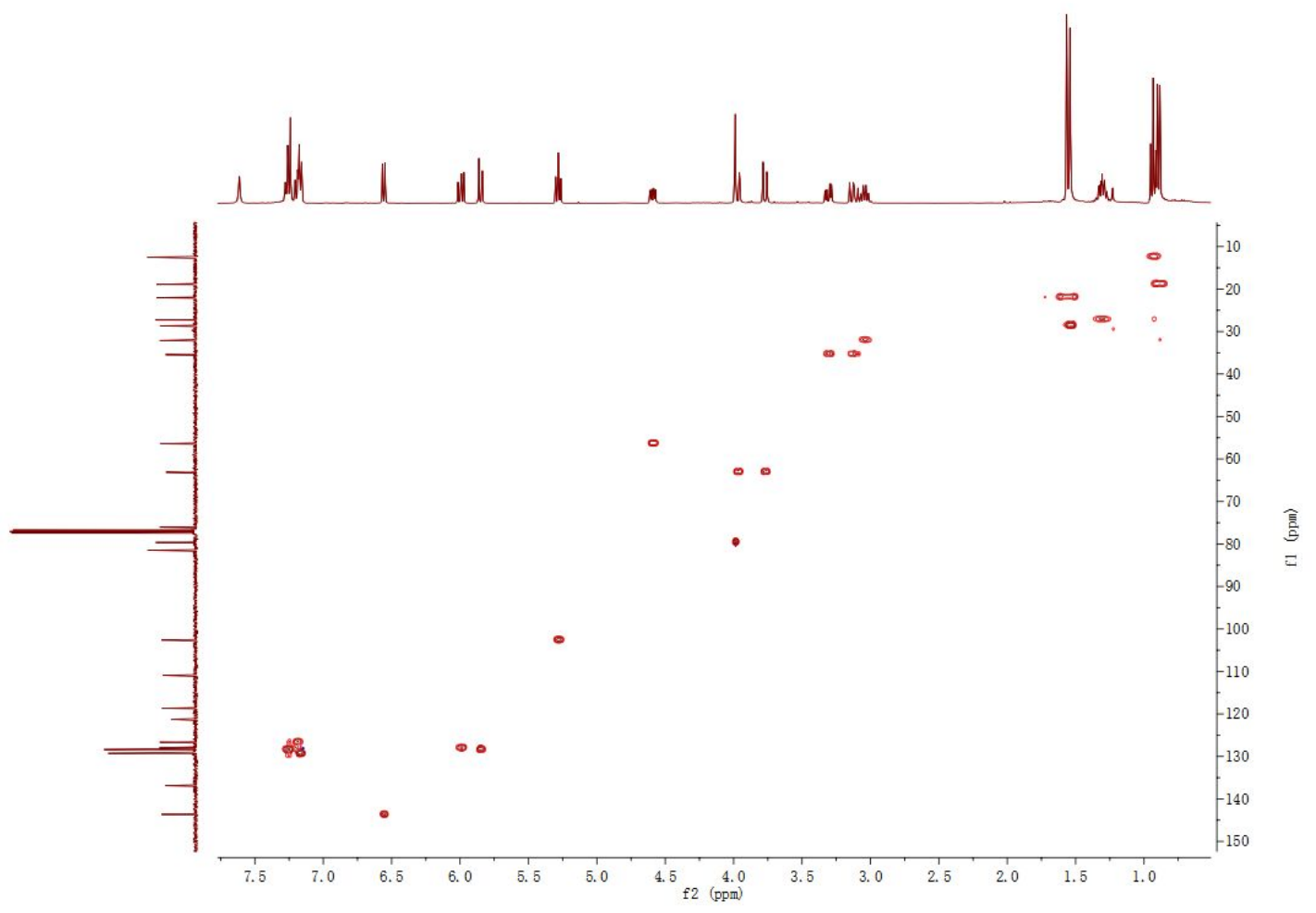

Figure S8. HMBC spectrum of compound 1 


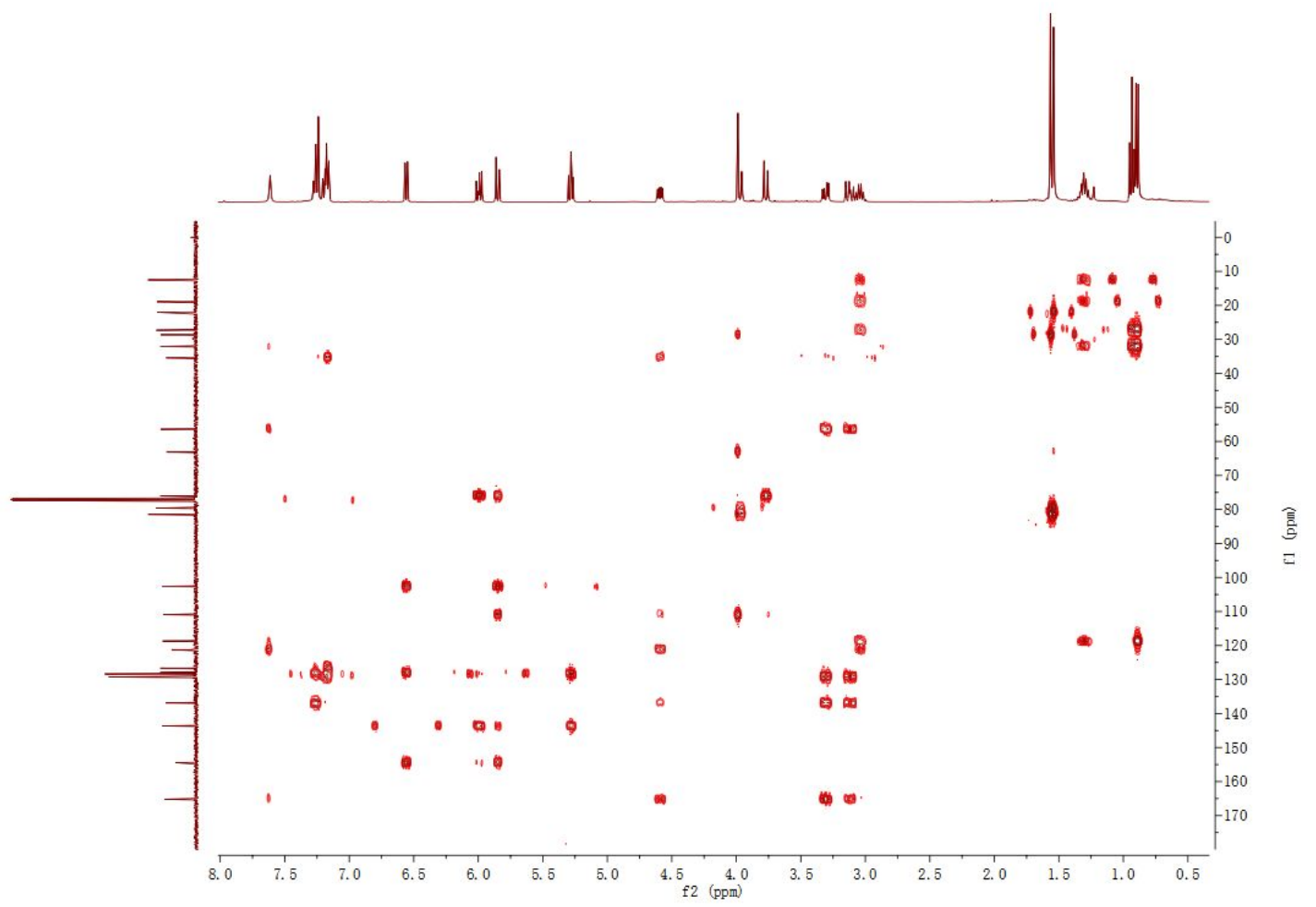

Figure S9. ${ }^{1} \mathrm{H}-{ }^{1} \mathrm{H}$ COSY spectrum of compound $\mathbf{1}$ 


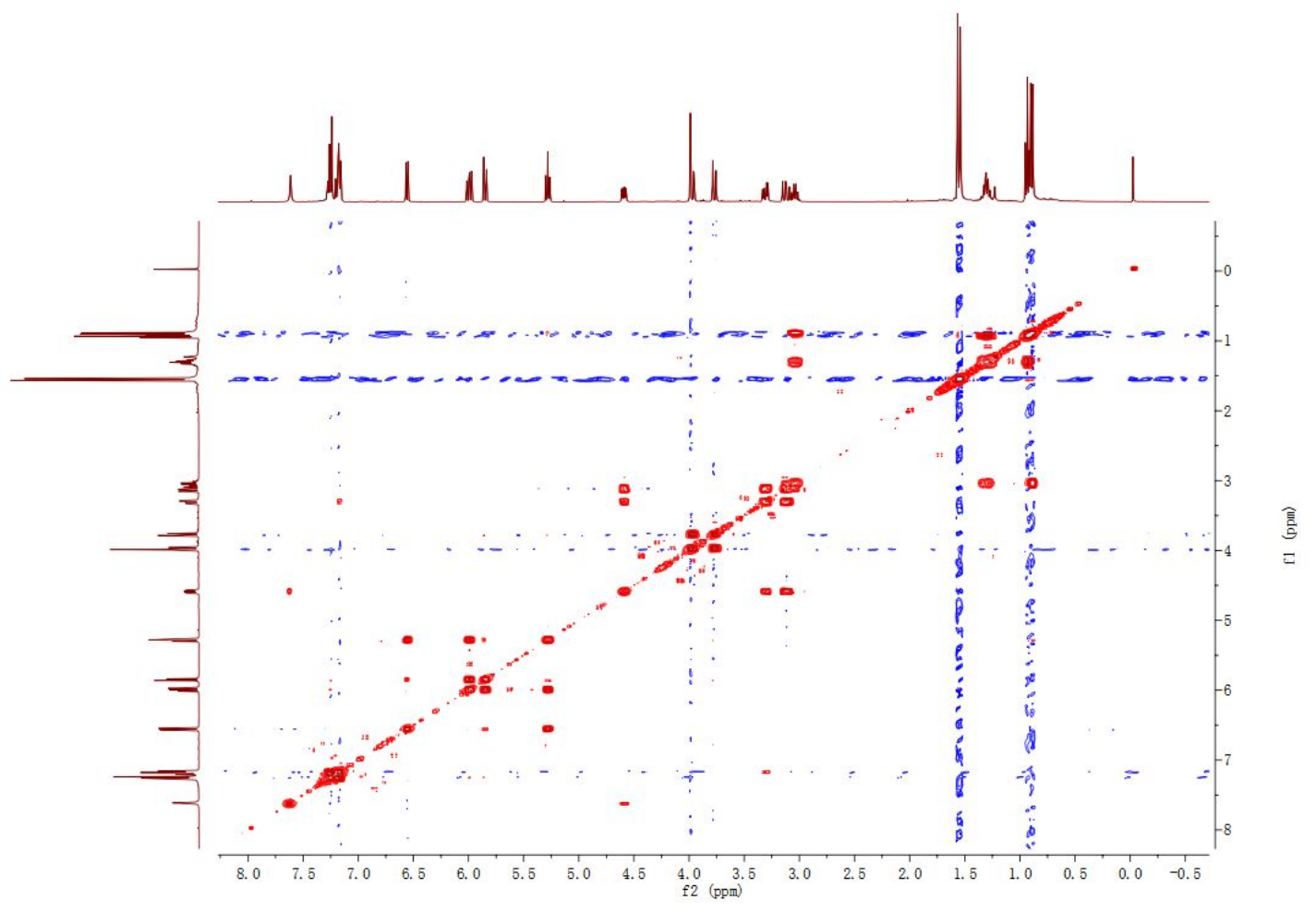

Figure S10. NOESY spectrum of compound 1

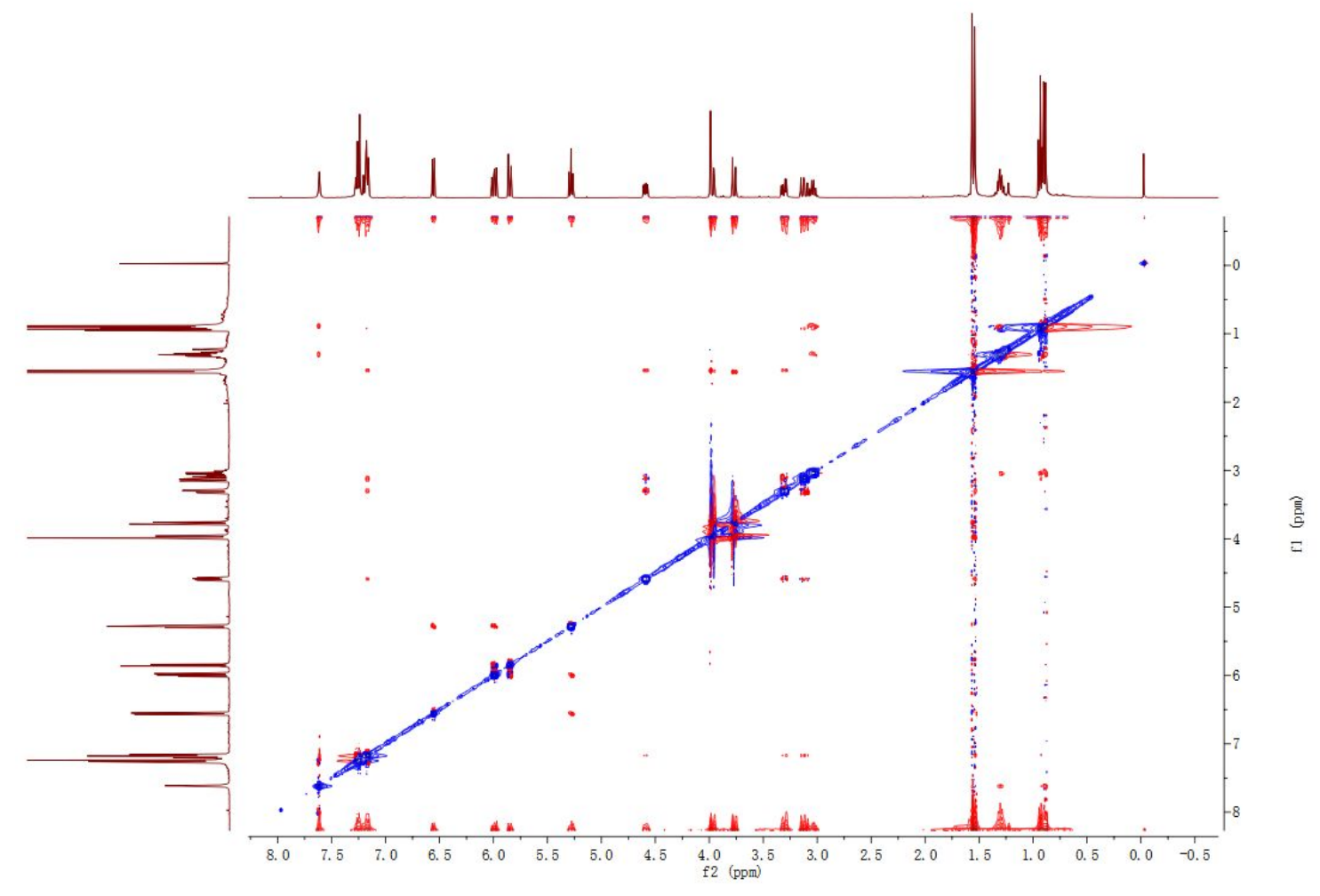


Figure S11. HR-ESI-MS spectrum of compound 1

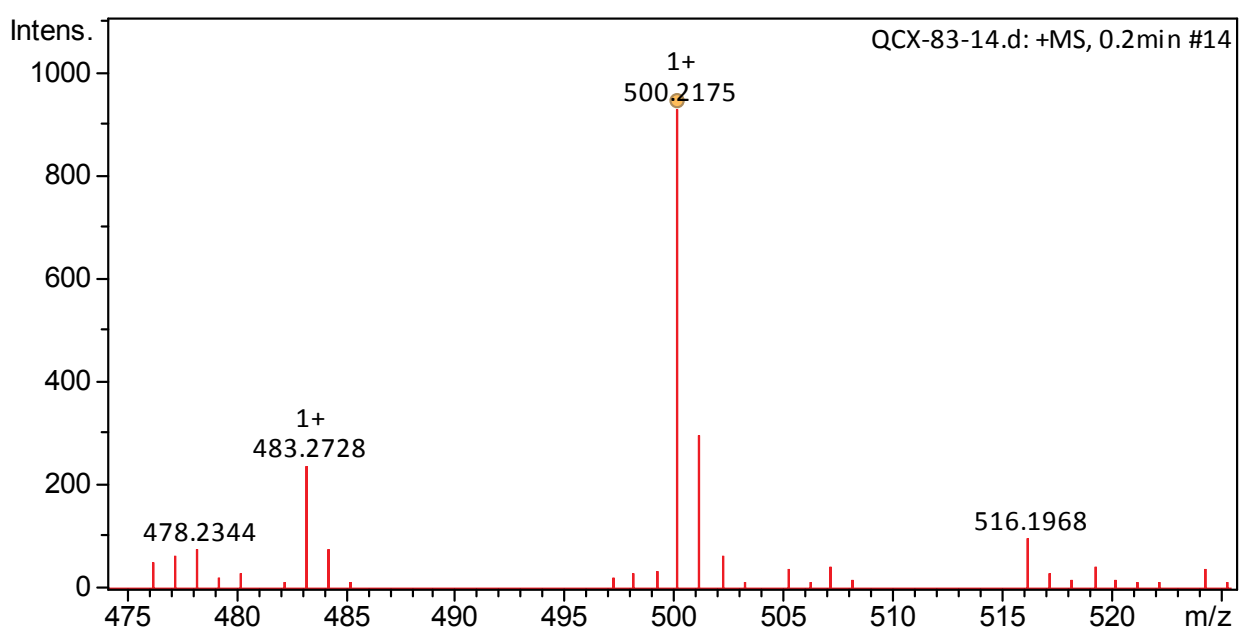

Figure S12. UV spectrum of compound 1

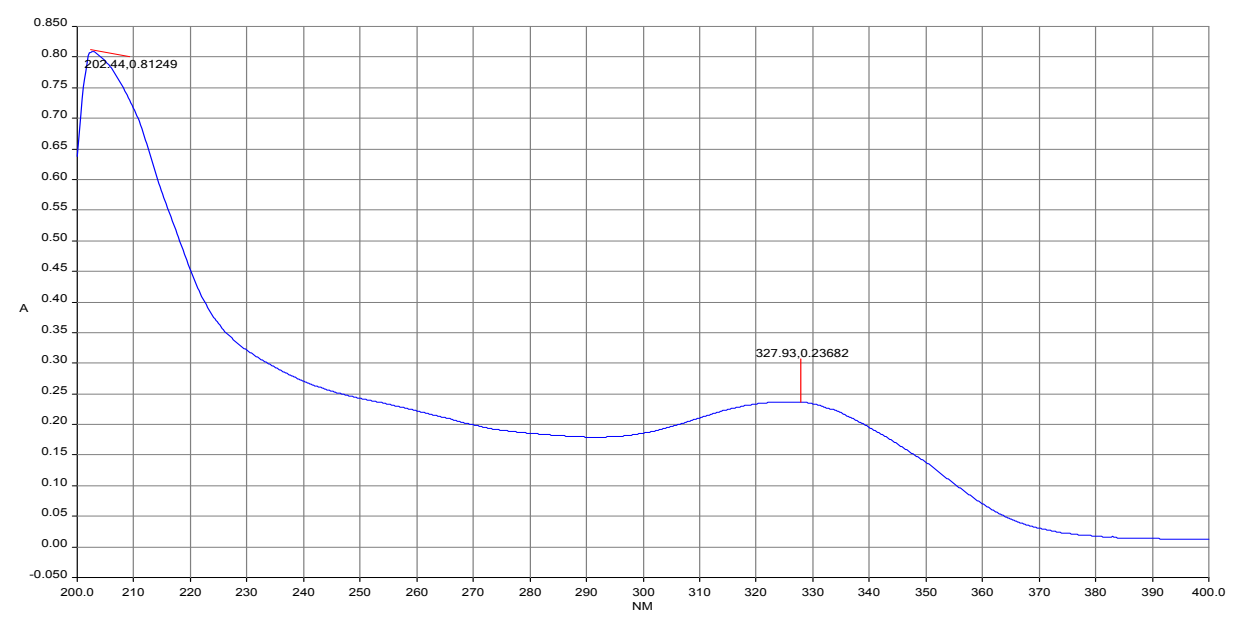

Figure S13. IR spectrum of compound 1 
E:|20190516120190516 $\square \square \mid 6.0$

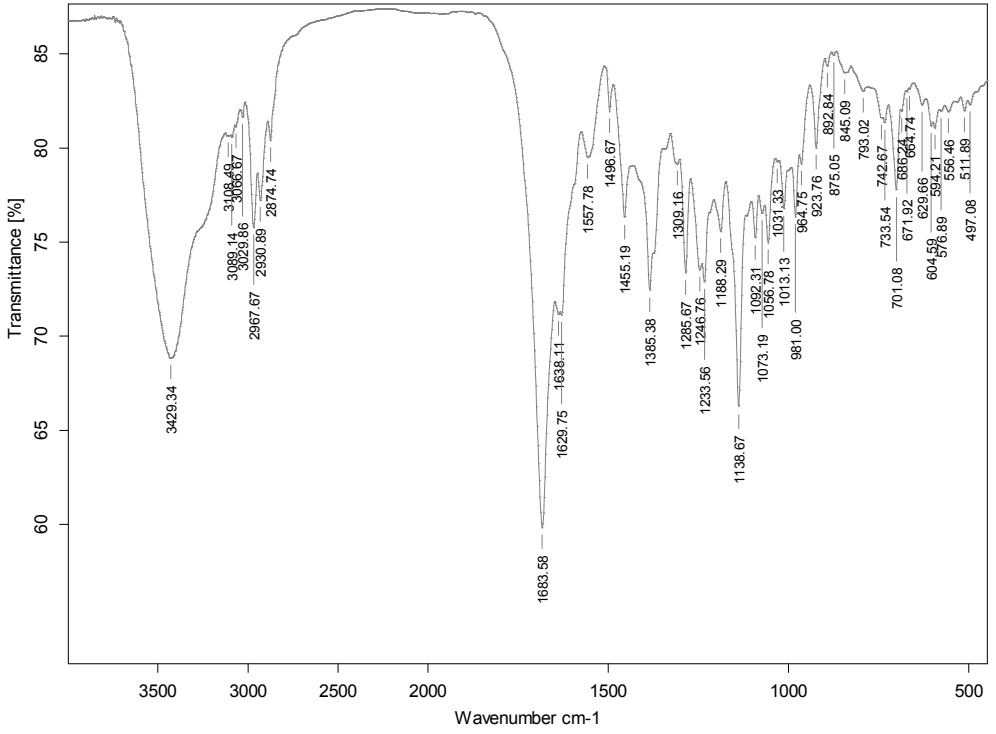

